\title{
Chromatography Profiles of Terpenoid Compounds in the Extract of Sambiloto (Andrographis Paniculata) Herb from Various Solvents
}

\section{Mohammad Fajar Hadi Salim*, I Made Arie Dharma Putra Nugraha, Farah Adilla, Luh Pratiwi Diva Yanti}

Department of Pharmacy, Faculty of Math and Science, Universitas Udayana, Kampus Unud-Jimbaran Street, Jimbaran-Bali, Indonesia 80364

*E-mail: hadi.salim@student.unud.ac.id

Received: 4 March 2021; Accepted: 22 July 2021; Published: 15 December 2021

\begin{abstract}
Sambiloto (Andrographis paniculata) is widely used as a medicinal plant for Indonesians. The content of extracted bioactive compounds is affected by the polarity of the extraction solvent. This study aims to determine the effect of extraction solvent on the chromatographic profile of Sambiloto herb, especially terpenoid group using the TLC-Spectrophotodensitometry method. Sambiloto herb was extracted by sonication method using methanol, ethanol, ethyl acetate, and chloroform as the solvents. Chromatographic profiles were identified by stationary phase of TLC silica gel $\mathrm{GF}_{254}$ plate and a mobile phase of chloroform:methanol $(10: 1 \mathrm{v} / \mathrm{v})$, observed visually, and scanned at $210 \mathrm{~nm}$. The plate was sprayed with anisadehyd-sulfuric acid reagent and observed visually. The compounds that belong to terpenoid compounds, namely S2, S5, S8, S11, and S12, had a greater percentage of peak area than the total area so that they were categorized as major components. The extraction solvent for Sambiloto herb that provides the best chromatographic profiles was found in the solvent of methanol extraction.
\end{abstract}

Keywords: Extraction solvent; Chromatographic profiles; Terpenoid; Sambiloto herb

\section{Introduction}

Sambiloto (Andrographis paniculata) is widely used as a medicinal plant for the people of Indonesia, one of which is used as bitter herbal drink (Widjajakusuma et al., 2019). In addition to its bitter taste, Sambiloto is rich in various pharmacological activities which include antidiabetic, antipyretic, antibacterial, anticancer, antiinflammatory, antimalarial, antioxidant, hepatoprotective and also used for such treatment of diseases caused by immune disorders such as HIV and AIDS (Cui et al., 2009; Widjajakusuma et al., 2019). The various pharmacological activities produced by Sambiloto are caused by the content of bioactive compounds of the diterpene lactone group, including andrographolide, dehydroandrographolide, neoandrographolide, and deoxyandrographolide (Rafi et al., 2020).

The content of various bioactive compounds can be influenced by various factors, including genetics, growing location, changing seasons, harvest time, postharvest processes, and various processing methods (Li et al., 2008; Sharma and Sharma, 2013). In the progress of processing Sambiloto (Andrographis paniculata), particularly, the use of extraction solvents is very influential on the extraction process of bioactive compounds 
from the matrix of Sambiloto (El Houda Lezoul et al., 2020). The content of extracted bioactive compounds is strongly affected by the polarity of the extraction solvent used. Therefore, it is necessary to control the quality of the content of bioactive compounds from Sambiloto extraction process to ensure the amount of bioactive compounds extracted in order to produce consistent therapeutic activity (Cui et al., 2009; Sultana, Anwar and Ashraf, 2009).

One of the methods commonly used in the process of controlling the quality of bioactive compounds from a medicinal plant is through a chromatographic profile using the TLC-Spectrophotodensitometry method. Identification of chromatographic profiles will have a significant effect on the quality control process of raw materials, especially Sambiloto (Andrographis paniculata), with the emphasis on characterizing the composition of the sample (Wang et al., 2007). Various studies that exist until now are still limited to the comparison of andrographolide levels obtained in different extraction solvents, but have not provided an overview of the different chromatographic profiles of the terpenoid compound groups in the produced Sambiloto (Andrographis paniculata) herb due to the differences in extraction solvents. Based on the explanation above, this study aims to determine the effect of the type of extraction solvent on the chromatographic profile of Sambiloto (Andrographis paniculata) herb, especially terpenoid group using the TLC-Spectrophotodensitometry method.

\section{Methodology}

Materials

The tools used in this study included analytical balance (Kern-Alj®), Erlenmeyer (Iwaki-Pyrex $®$ ), sonicator, filter paper, measuring flask (Iwaki-Pyrex®), measuring pipette (Iwaki-Pyrex $®$ ), beaker ( IwakiPyrex®), silica gel TLC plate GF254, Automatic TLC Sampler 4 (CAMAG), ADC chamber (CAMAG), sprayer, TLC Visualizer (CAMAG), and spectrophotodensitometer
CAMAG TLC Scanner 4. The material in this study was a sample of Sambiloto (Andrographis paniculata) herb coming from Majene Regency, West Sulawesi Province, in the form of rough powder and had been dried. Various solvents and reagents used in this study included methanol P (Merck $®)$ ), ethanol P (Merck $®)$ ), ethyl acetate $P$ (Merck®), chloroform $P$ (Merck $($ ), concentrated sulfuric acid $P$ (Merck $®$ ), and P -anisaldehyde (Merck®).

\section{Sample Preparation}

Sambiloto (Andrographis paniculata) herb powder from Majene Regency, West Sulawesi Province was prepared. 1 gram of Sambiloto powder was weighed. Then, the sample was extracted by sonication method using a sonicator for 30 minutes. The extraction solvent that was used consisted of four different types of solvents, namely methanol, ethanol, ethyl acetate, and chloroform; each of which amounts to 20 $\mathrm{mL}$. The extract was then filtered and put into a vial.

\section{Identification of Chromatographic Profile}

The sample solution of Sambiloto (Andrographis paniculata) extract was sprinkled on the plates with $10 \mu \mathrm{L}$ for each with an Automatic TLC Sampler 4. The plates were eluted with mobile phase chloroform:methanol $(10: 1 \mathrm{v} / \mathrm{v})$ in a saturated chamber with an elution distance of $8 \mathrm{~cm}$. The selection of the mobile phase was based on the better chromatogram results of the terpenoid compound group due to the absence of tailings in the chromatogram, to facilitate the process of further analysis and identification (Samirana et al., 2017). The plate was then observed visually with TLC Visualizer, under white rays, UV rays $254 \mathrm{~nm}$, and UV rays $366 \mathrm{~nm}$. The observed plates were scanned at a wavelength of $210 \mathrm{~nm}$. The plate was then sprayed with anisadehidsulfuric acid spotting reagent and heated at $110^{\circ} \mathrm{C}$ for 5 minutes. Changes in the color of the spots on the plate were observed again under the white rays. The presence of purplish-red spots indicates the existence of 
terpenoid group compounds (Wagner and Bladt, 2001).

\section{Result and Discussion}

Qualitatively, the results of visualization of TLC plates from methanol and ethanol extracts of Sambiloto (A. paniculata) before derivatization under UV rays of $254 \mathrm{~nm}, 366 \mathrm{~nm}$ and the white ray, and after derivatization with anisaldehydesulfuric acid $\mathrm{P}$, are consecutively shown in
Fig 1. The resulting spot color changes are tabulated in Table 1. The compounds found in the methanol extract were $12 ; 5$ of which were terpenoids compounds, namely S2 (Rf 0.20); S5 (Rf 0.42); S8 (Rf 0.71); S11 (Rf $.95)$; and S12 ( $\operatorname{Rf} 0.97)$. The number of compounds found in the ethanol extract was $10 ; 5$ of which were terpenoids, namely S2 (Rf 0.20); S5 (Rf 0.40); S8 (Rf 0.69); S11 (Rf $0.94) ;$ and $S 12$ (Rf 0.98).

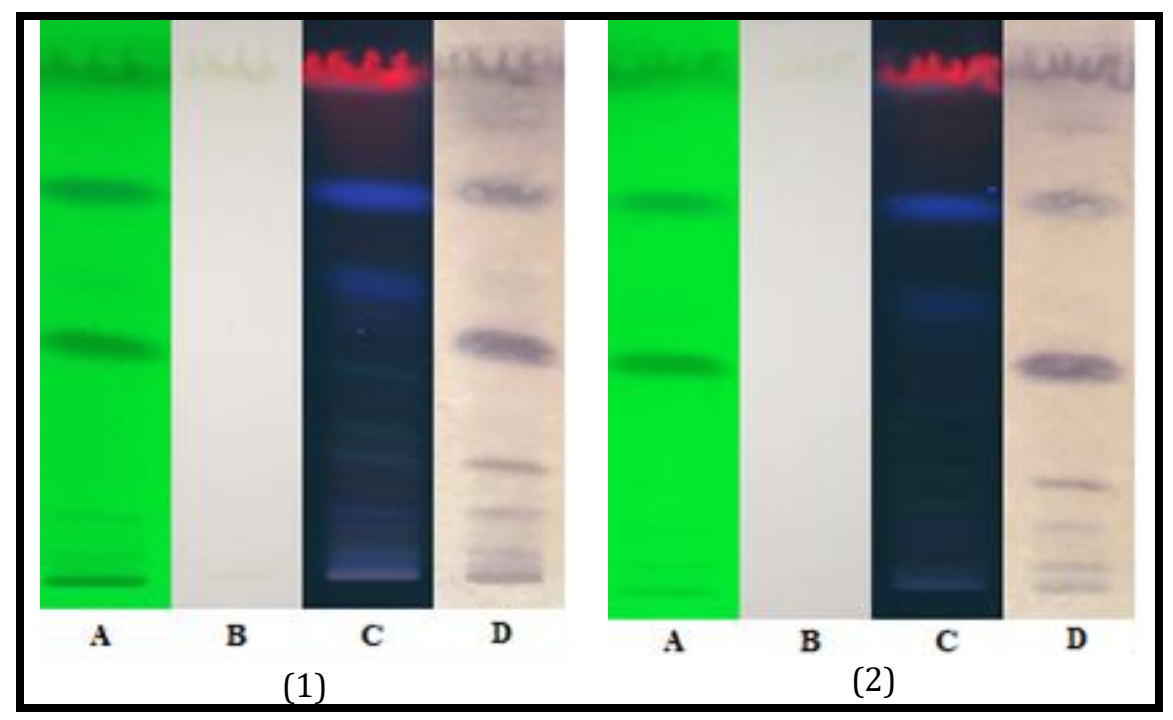

Fig 1. The TLC Visualization of [1] Methanol and [2] Ethanol Extract at [A] UV $254 \mathrm{~nm}$ [B] White Rays [C] UV $366 \mathrm{~nm}$, [D] White Rays after Derivatization

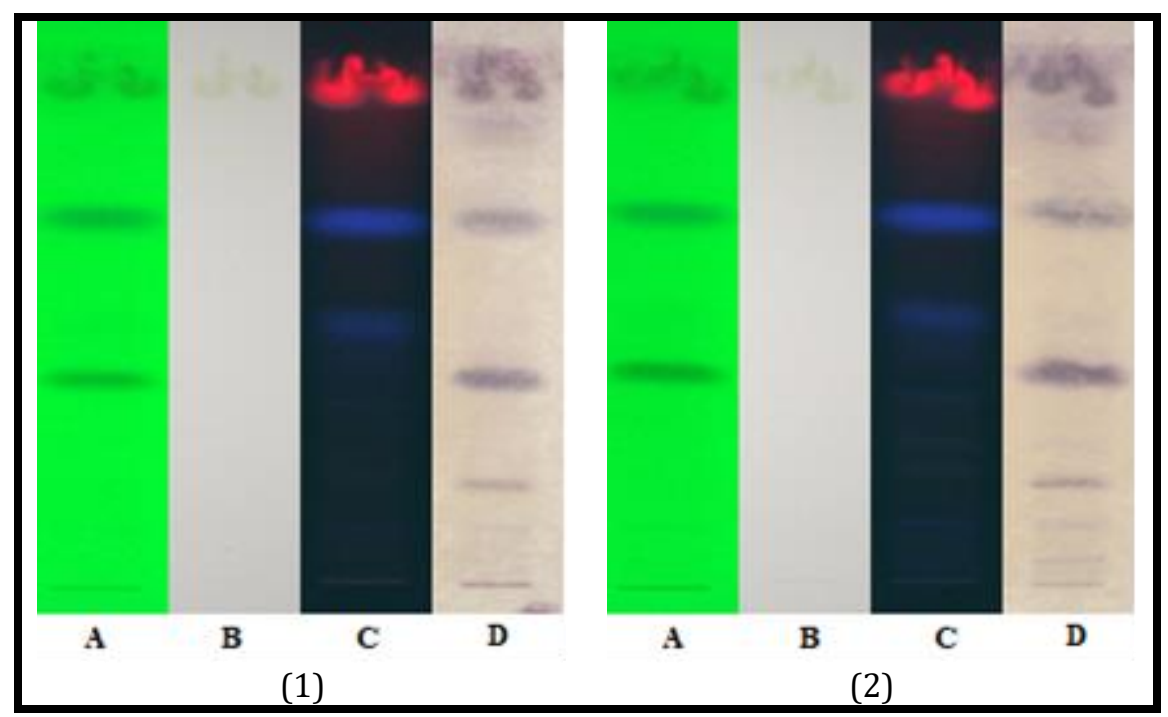

Fig 2. The TLC Visualization of [1] Ethyl Acetate and [2] Chloroform Extract at [A] UV $254 \mathrm{~nm}$ [B] White Rays [C] UV 366 nm, [D] White Rays after Derivatization 
Table 1. The Visualization of TLC Plate Color of Methanol, Etanol, Ethyl Acetate and Chloroform Extract

\begin{tabular}{|c|c|c|c|c|c|c|c|c|c|c|}
\hline \multirow{3}{*}{ Compounds } & \multicolumn{5}{|c|}{ Methanol } & \multicolumn{5}{|c|}{ Ethanol } \\
\hline & \multirow{2}{*}{ Rf } & \multicolumn{3}{|c|}{ Before derivatization } & \multirow{2}{*}{$\begin{array}{c}\text { After } \\
\text { derivatization } \\
\text { White Rays }\end{array}$} & \multirow{2}{*}{$\mathrm{Rf}$} & \multicolumn{3}{|c|}{ Before derivatization } & \multirow{2}{*}{$\begin{array}{c}\text { After } \\
\text { derivatization } \\
\text { White Rays }\end{array}$} \\
\hline & & $254 \mathrm{~nm}$ & $\begin{array}{c}\text { White } \\
\text { Rays }\end{array}$ & $366 \mathrm{~nm}$ & & & $254 \mathrm{~nm}$ & $\begin{array}{c}\text { White } \\
\text { Rays }\end{array}$ & $366 \mathrm{~nm}$ & \\
\hline $\mathrm{S} 1$ & 0.12 & Grey & - & $\begin{array}{l}\text { Light } \\
\text { Blue }\end{array}$ & Grey & 0.12 & Grey & - & $\begin{array}{l}\text { Light } \\
\text { Blue }\end{array}$ & Grey \\
\hline $\mathrm{S} 2$ & 0.20 & - & - & Grey & Black* & 0.20 & - & - & Grey & Violet* \\
\hline S3 & 0.28 & - & - & Grey & - & 0.27 & - & - & - & - \\
\hline S4 & 0.35 & - & - & - & - & - & - & - & - & - \\
\hline S5 & 0.42 & Black & - & Grey & Black* & 0.40 & Black & - & Grey & Violet* \\
\hline S6 & 0.52 & - & - & Grey & - & 0.50 & - & - & Grey & - \\
\hline S7 & 0.60 & - & - & $\begin{array}{l}\text { Light } \\
\text { Blue }\end{array}$ & - & 0.59 & - & - & $\begin{array}{l}\text { Light } \\
\text { Blue }\end{array}$ & - \\
\hline S8 & 0.71 & Black & - & Blue & Black* & 0.69 & Black & - & Blue & Violet* \\
\hline S9 & 0.80 & - & - & Pink & - & - & - & - & - & - \\
\hline S10 & 0.85 & - & $\begin{array}{l}\text { Light } \\
\text { Brown }\end{array}$ & Pink & Grey & 0.83 & - & $\begin{array}{l}\text { Light } \\
\text { Brown }\end{array}$ & Pink & Grey \\
\hline S11 & 0.95 & Black & Brown & Red & Violet* & 0.94 & Black & Brown & Red & Violet* \\
\hline $\mathrm{S} 12$ & 0.97 & Black & Brown & Red & Violet* & 0.98 & Black & Brown & Red & Violet* \\
\hline \multirow{3}{*}{ Compounds } & \multicolumn{5}{|c|}{ Ethyl Acetate } & \multicolumn{5}{|c|}{ Chloroform } \\
\hline & \multirow[t]{2}{*}{$\mathrm{Rf}$} & \multicolumn{3}{|c|}{ Before derivatization } & $\begin{array}{c}\text { After } \\
\text { derivatization }\end{array}$ & \multirow{2}{*}{$\mathrm{Rf}$} & \multicolumn{3}{|c|}{ Before derivatization } & $\begin{array}{c}\text { After } \\
\text { derivatization }\end{array}$ \\
\hline & & $254 \mathrm{~nm}$ & $\begin{array}{l}\text { White } \\
\text { Rays }\end{array}$ & $366 \mathrm{~nm}$ & White Rays & & $254 \mathrm{~nm}$ & $\begin{array}{l}\text { White } \\
\text { Rays }\end{array}$ & $366 \mathrm{~nm}$ & White Rays \\
\hline S1 & 0.12 & Grey & - & $\begin{array}{l}\text { Light } \\
\text { Blue }\end{array}$ & Grey & 0.11 & - & - & $\begin{array}{l}\text { Light } \\
\text { Blue }\end{array}$ & Grey \\
\hline $\mathrm{S} 2$ & 0.19 & - & - & - & Violet* & 0.19 & - & - & - & Grey \\
\hline S3 & 0.26 & - & - & Grey & - & 0.24 & - & - & Grey & - \\
\hline S4 & - & - & - & - & - & - & - & - & - & - \\
\hline S5 & 0.39 & Black & - & Grey & Violet* & 0.38 & Black & - & Grey & Violet* \\
\hline S6 & 0.50 & - & - & $\begin{array}{l}\text { Light } \\
\text { Blue }\end{array}$ & - & 0.48 & - & - & $\begin{array}{l}\text { Light } \\
\text { Blue }\end{array}$ & - \\
\hline S7 & - & - & - & - & - & - & - & - & - & - \\
\hline S8 & 0.68 & Black & - & Blue & Violet* & 0.68 & Black & - & Blue & Violet* \\
\hline S9 & - & - & - & - & - & - & - & - & - & - \\
\hline S10 & 0.83 & - & $\begin{array}{l}\text { Light } \\
\text { Brown }\end{array}$ & Pink & Grey & 0.83 & - & $\begin{array}{l}\text { Light } \\
\text { Brown }\end{array}$ & Pink & Grey \\
\hline S11 & 0.91 & Black & Brown & Red & Violet* & 0.92 & Black & Brown & Red & Violet* \\
\hline S12 & 0.97 & Black & Brown & Red & Violet* & 0.97 & Black & Brown & Red & Violet* \\
\hline
\end{tabular}

* The positive one indicates a group of terpenoid compounds.

The results of visualization of TLC plates of ethyl acetate and chloroform extract of Sambiloto (Andrographis paniculata) before derivatization under UV rays of $254 \mathrm{~nm}, 366 \mathrm{~nm}$ and white rays, and after derivatization with anisaldehydesulfuric acid $\mathrm{P}$, are shown in Fig 2 . The resulting spot color changes are tabulated in Table 1. The compounds found in the ethyl acetate extract were $10 ; 5$ of which were terpenoids, namely S2 (Rf 0.20); S5 (Rf 0.42); S8 (Rf 0.71); S11 (Rf .95); and S12 (Rf 0.97). Compounds found in the chloroform extract were 9; 4 of which were terpenoids, namely S5 (Rf 0,40); S8 (Rf 0.69); S11 (Rf 0.94); and S12 (Rf 0.98).

Based on the resulting chromatogram, the percentage of the area ratio of each compound in each extract, namely methanol, ethanol, ethyl acetate, and chloroform are shown in Table 2. In the four other extracts, the bioactive compounds belonging to the class of terpenoid compounds, namely S2, S5, S8, S11, and S12, had a higher percentage of peak area than the total area so that it was categorized as a major component compared to other compounds classified as minor components in Sambiloto (Andrographis paniculata). On the other hand, a compound categorized as a major component has a peak area of more than $5 \%$ of the total area (Shakila et al., 2014). The methanol solvent yielded a peak area of $7.34 \%$ (S2); $41.80 \%$ (S5); $19.82 \%$ (S8); $16.04 \%$ (S11); and 5.38\% (S12). The ethanol solvent reached a peak area of 
$5.59 \% \quad(\mathrm{~S} 2) ; \quad 33.43 \% \quad(\mathrm{~S} 5) ; \quad 17.10 \%$ (S8); $23.41 \%$ (S11), and $12.26 \%$ (S12). The ethyl acetate solvent gained a peak area of $4.45 \%$ (S2); $23.35 \%$ (S5); 19.12\% (S8); $11.17 \%$ (S11), and 31.87\% (S12). The last but not least, chloroform solvent produced a peak area of $16.18 \%$ (S5); $16.51 \%$ (S8); $24.55 \%$ (S11); and $32.35 \%$ (S12). This indicates the ability of various extraction solvents to extract terpenoid compounds in Sambiloto (Andrographis paniculata) herb.

Table 2. The Area Percentage of Each Peak from The Extract of Methanol, Ethanol, Ethyl Acetate and Chloroform of Sambiloto Herb (Andrographis paniculata) at $210 \mathrm{~nm}$

\begin{tabular}{|c|c|c|c|c|c|c|c|c|c|c|c|c|}
\hline \multirow[b]{2}{*}{ Compounds } & \multicolumn{3}{|c|}{ Methanol } & \multicolumn{3}{|c|}{ Ethanol } & \multicolumn{3}{|c|}{ Ethyl Acetate } & \multicolumn{3}{|c|}{ Chloroform } \\
\hline & Rf & AUC & $\begin{array}{c}\text { \% Area } \\
\text { of } \\
\text { Peak }\end{array}$ & $\mathrm{Rf}$ & AUC & $\begin{array}{c}\text { \% Area } \\
\text { of } \\
\text { Peak }\end{array}$ & $\mathrm{Rf}$ & AUC & $\begin{array}{c}\text { \% Area } \\
\text { of } \\
\text { Peak }\end{array}$ & $\mathrm{Rf}$ & AUC & $\begin{array}{c}\% \text { Area } \\
\text { of } \\
\text { Peak }\end{array}$ \\
\hline S1 & 0.12 & 1075.1 & $2.45 \%$ & 0.12 & 490.8 & $1.50 \%$ & 0.12 & 430.7 & $3.29 \%$ & 0.11 & 298.7 & $1.09 \%$ \\
\hline $\mathrm{S} 2$ & 0.20 & 3217.5 & $7.34 \%$ & 0.20 & 1826.5 & $5.59 \%$ & 0.19 & 581.9 & $4.45 \%$ & 0.19 & 775.2 & $2.83 \%$ \\
\hline S3 & 0.28 & 559.4 & $1.28 \%$ & 0.27 & 370.4 & $1.13 \%$ & 0.26 & 125.7 & $0.96 \%$ & 0.24 & 96.8 & $0.35 \%$ \\
\hline S4 & 0.35 & 337.0 & $0.77 \%$ & - & - & - & - & 55.4 & $0.42 \%$ & - & - & - \\
\hline S5 & 0.42 & 18319.2 & $41.80 \%$ & 0.40 & 10925.3 & $33.43 \%$ & 0.39 & 3054.1 & $23.35 \%$ & 0.38 & 4426.4 & $16.18 \%$ \\
\hline S6 & 0.52 & 712.4 & $1.63 \%$ & 0.50 & 635.5 & $1.94 \%$ & 0.50 & 205.7 & $1.57 \%$ & 0.48 & 603.1 & $2.20 \%$ \\
\hline S7 & 0.60 & 110.7 & $0.25 \%$ & 0.59 & 162.7 & $0.50 \%$ & - & - & - & - & - & - \\
\hline S8 & 0.71 & 8685.4 & $19.82 \%$ & 0.69 & 5590.2 & $17.10 \%$ & 0.68 & 2500.6 & $19.12 \%$ & 0.68 & 4518.0 & $16.51 \%$ \\
\hline S9 & 0.80 & 62.9 & $0.14 \%$ & - & - & - & - & - & - & - & - & - \\
\hline S10 & 0.85 & 1360.9 & $3.11 \%$ & 0.83 & 1024.1 & $3.13 \%$ & 0.83 & 494.6 & $3.78 \%$ & 0.83 & 1070.9 & $3.91 \%$ \\
\hline S11 & 0.95 & 7028.6 & $16.04 \%$ & 0.94 & 7650.5 & $23.41 \%$ & 0.91 & 1460.8 & $11.17 \%$ & 0.92 & 6717.1 & $24.55 \%$ \\
\hline S12 & 0.97 & 2358.8 & $5.38 \%$ & 0.98 & 4005.7 & $12.26 \%$ & 0.97 & 4168.0 & $31.87 \%$ & 0.97 & 8850.7 & $32.35 \%$ \\
\hline
\end{tabular}

Based on the above explanation, it shows that each extraction solvent is able to extract compounds with varying amounts of compounds and the Area Under the Curve (AUC) value of each compound. This result highly notes that the methanol extraction solvent is able to provide the best chromatographic profile, which can be seen from the amount of the produced methanol compound along with the AUC value of each compound. Similar results have been reported by Shakila, Elankani and Jegajothipandian (2014), Avanigadda and Vangalapati (2010), and Kumoro and Hasan (2006). Shakila, Elankani and Jegajothipandian (2014) reported that there were differences in solvent extraction of Sambiloto (Andrographis paniculata), including ethanol, ethyl acetate, and chloroform. The differences refer to the solvent extraction of Sambiloto (Andrographis paniculata) which produced different peak amounts of compounds when analyzed by TLC method, with the mobile phase toluene:ethyl acetate $(5: 1 \mathrm{v} / \mathrm{v})$ for chloroform extract and mobile phase ethyl acetate:methanol $(10: 1 \mathrm{v} / \mathrm{v})$ for ethyl acetate extract. The ethanol extraction solvent produced 13 peaks, with the peak area percentage of the major compounds was $32.43 \%$ ( $\operatorname{Rf} 0.5$ ) and $13.21 \%$ (Rf 0.87). The solvent extraction of ethyl acetate obtained 11 peaks, with the peak area percentage of the major compounds was $25.69 \%$ (Rf 0.78), 23.07\% (Rf 0.93), 18.23\% (Rf 0.89), and 11. 0.06\% (Rf 0.84). The solvent extraction of chloroform gained 21 peaks, with the peak area percentage of the major compounds was $30.79 \%$ (Rf 0.06), $21.48 \%$ (Rf 0.73), and 16.76\% (Rf 0.94). In this study, the mobile phase used was judged unable to separate the terpenoid group compounds properly because the peaks in the resulting chromatogram experienced tailings so that the analysis and identification process of the chromatogram 
profile was difficult to carry out. Therefore, in this study, the elution process used the mobile phase of chloroform: methanol (10:1 $\mathrm{v} / \mathrm{v}$ ), which has been proven to produce good chromatograms, with peaks belonging to the terpenoid compound group that do not experience tailings (Schibli and Reich, 2005; Samirana et al., 2017).

Avanigadda and Vangalapati (2010) reported that differences in extraction solvents such as ethyl acetate, ethanol and methanol were able to influence the yield and levels of andrographolide extracted when analyzed by the HPLC method. The yield of ethyl acetate, ethanol and methanol extraction solvents was 14.619\%; 18.490\% and $\quad 15.518 \%$, respectively. Andrographolide levels in ethyl acetate, ethanol and methanol extraction solvents were $0.452 ; 0.128$ and 0.131 gram $/ 1$ gram of dry leaves. Finally, Kumoro and Hasan (2006) reported similar results regarding the effect of different extraction solvents such as methanol, ethanol, chloroform and ethyl acetate on the yield and levels of andrographolide extracted from Sambiloto (Andrographis paniculata) when analyzed by HPLC method. The yield of methanol, ethanol, ethyl acetate and chloroform extraction solvents was $32.11 \%$; $33.15 \%$; $12.65 \%$ and $12.00 \%$, respectively. Andrographolide levels in the extraction solvents of methanol, ethanol, ethyl acetate, and chloroform were $0.1140 ; 0.1010$; 0.0591 and 0.0517 gram/1 gram of dry leaves, respectively.

The qualitative and quantitative differences in the results of the terpenoid group of compounds between each extraction solvent are based on the nature of the polarity of the solvent itself. This is associated with the higher solubility of terpenoid compounds in methanol extraction solvents, as seen from the high AUC values of S2, S5, and S8 compounds, compared to other tested solvents, such as ethanol, ethyl acetate, and chloroform (Truong et al., 2019). Methanol solvent in its structure contains polar $(-\mathrm{OH})$ and nonpolar (-CH3) groups so that it is able to extract terpenoid group compounds that have polar and non-polar groups (Astarina,
N. W. G., Astuti, K. W., Warditiani, 2012). In their structure, terpenoids have a cyclic alcohol group that contributes to their polarity. However, keep in mind that terpenoids are composed of long-chain carbon atoms so that the polarity of terpenoids can tend to be non-polar, which results in terpenoids being easily extracted in non-polar solvents, which is seen from the high AUC values of compounds S11 and S12 in ethyl acetate and chloroform solvents compared to other solvents. Therefore, the different types of extraction solvents will give different results of the chromatographic profiles of different groups of terpenoid compounds.

\section{Conclusion}

The extraction solvent for Sambiloto (Andrographis paniculata) herb which gives the best chromatographic profile is found in the methanol extraction solvent. This is based on the difference in polarity of each solvent, namely methanol, ethanol, ethyl acetate, and chloroform, as well as variations in the polarity of the terpenoid compound group in Sambiloto (Andrographis paniculata) herb, which results in the variation of the chromatographic profiles obtained.

\section{Acknowledgement}

Thank you to Universitas Udayana for providing space and facilities in carrying out this research, as well as all parties who helped in this research.

\section{Reference}

Astarina, N. W. G., Astuti, K. W., Warditiani, N. K. (2012) 'Skrining Fitokimia Ekstrak Metanol Rimpang Bangle (Zingiber purpureum Roxb.)', Jurnal Farmasi Udayana, 344(4), pp. 1-7.

Avanigadda, S. and Vangalapati, M. (2010) 'Experimental and Modelling Studies of Andrographolide Extraction from Andrographis paniculata', International Journal of Chemical, Environmental and Pharmaceutical 
Research, 1(1), pp. 32-36.

Cui, Y. et al. (2009) 'Fingerprint Profile of Active Components for Andrographis paniculata Nees by HPLC-DAD', Sensing and Instrumentation for Food Quality and Safety, 3(3), pp. 165-179.

El Houda Lezoul, N. et al. (2020) 'Extraction Processes with Several Solvents on Total Bioactive Compounds in Different Organs of Three Medicinal Plants', Molecules, 25(20), pp. 1-15.

Kumoro, A. C. and Hasan, M. (2006) 'Experimental and Modelling Studies of Andrographolide Extraction from Andrographis paniculata', in University of Malaya ShortTerm Research Dissemnination. University of Malaya, pp. 1-4.

Li, S. et al. (2008) 'Chemical Markers for The Quality Control of Herbal Medicines: An Overview', Chinese Medicine, 3(7), pp. 1-16.

Rafi, M. et al. (2020) 'Classification of Andrographis paniculata Extracts by Solvent Extraction using HPLC fingerprint and Chemometric Analysis', BMC Research Notes. BioMed Central, 13(1), pp. 1-6.

Samirana, P. O. et al. (2017) 'Penentuan Profil Kandungan Kimia Ekstrak Etanol Daun Binahong (Anredera scandens (L.) Moq.)', Jurnal Farmasi Udayana, 6(1), pp. 23-33.

Schibli, A. and Reich, E. (2005) 'Modern TLC: A Key Technique for Identification and Quality Control of Botanicals and Dietary Supplements', Journal of Planar Chromatography - Modern TLC, 18(1), pp. 34-38.

Shakila, R., Elankani, P. and Jegajothipandian, S. (2014) 'Development of Fingerprint Profiles for Androgrphis echioides Nees. and Andrographis paniculata Nees.', Research Journal of Pharmacognosy and Phytochemistry, 6(1), pp. 22-29.

Sharma, M. and Sharma, R. G. (2013) 'Identification, Purification and Quantification of Andrographolide from Andrographis paniculata
(Burm. F.) Nees by HPTLC at Different Stages of Life Cycle of Crop.', Journal of Current Chemical \& Pharmaceutical Sciences, 3(1), pp. 23-32.

Sultana, B., Anwar, F. and Ashraf, M. (2009) 'Effect of Extraction Solvent/Technique on the Antioxidant Activity of Selected Medicinal Plant Extracts', Molecules, 14(6), pp. 2167-2180.

Truong, D. H. et al. (2019) 'Evaluation of The Use of Different Solvents for Phytochemical Constituents, Antioxidants, and In Vitro AntiInflammatory Activities of Severinia buxifolia', Journal of Food Quality, 2019(1), pp. 1-9.

Wagner, H. and Bladt, S. (2001) Plant Drugs Analysis: $\quad$ a Thin Layer Chromatography Atlas. 2nd Edition. Germany: Springer-Verlag Berlin Heidelberg.

Wang, S. et al. (2007) 'Fingerprint Quality Control of Angelica sinensis (Oliv.) Diels by High-Performance Liquid Chromatography Coupled with Discriminant Analysis', Talanta, 72(2), pp. 434-436..

Widjajakusuma, E. C. et al. (2019) 'Phytochemical Screening and Preliminary Clinical Trials of The Aqueous Extract Mixture of Andrographis paniculata (Burm. f.) Wall. ex Nees and Syzygium polyanthum (Wight.) Walp Leaves in Metformin Treated Patients with Type 2 Diabetes', Phytomedicine. Elsevier GmbH, 55(1), pp. 137-147. 